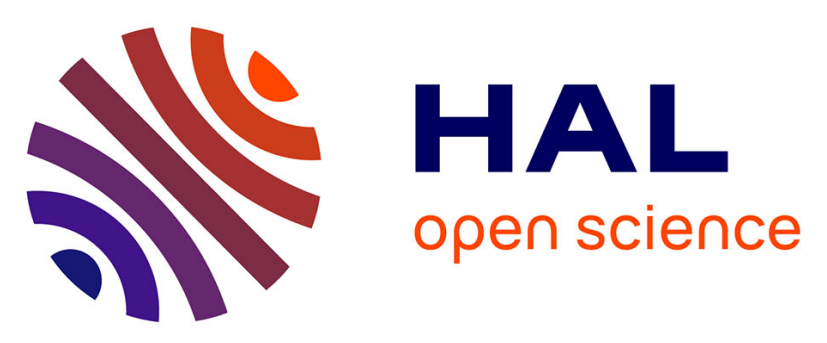

\title{
Natural gas shortages during the "coal-to-gas" transition in China have caused a large redistribution of air pollution in winter 2017
}

Siwen Wang, Hang Su, Chuchu Chen, Wei Tao, David G Streets, Zifeng Lu, Bo Zheng, Gregory R Carmichael, Jos Lelieveld, Ulrich Pöschl, et al.

\section{To cite this version:}

Siwen Wang, Hang Su, Chuchu Chen, Wei Tao, David G Streets, et al.. Natural gas shortages during the "coal-to-gas" transition in China have caused a large redistribution of air pollution in winter 2017. Proceedings of the National Academy of Sciences of the United States of America, 2020, 10.1073/pnas.2007513117/-/DCSupplemental.www.pnas.org/cgi/doi/10.1073/pnas.2007513117 . hal-03020653

\section{HAL Id: hal-03020653 https://hal.science/hal-03020653}

Submitted on 24 Nov 2020

HAL is a multi-disciplinary open access archive for the deposit and dissemination of scientific research documents, whether they are published or not. The documents may come from teaching and research institutions in France or abroad, or from public or private research centers.
L'archive ouverte pluridisciplinaire HAL, est destinée au dépôt et à la diffusion de documents scientifiques de niveau recherche, publiés ou non, émanant des établissements d'enseignement et de recherche français ou étrangers, des laboratoires publics ou privés. 


\title{
Natural gas shortages during the "coal-to-gas" transition in China have caused a large redistribution of air pollution in winter 2017
}

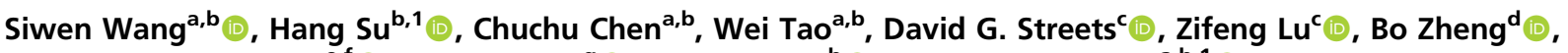

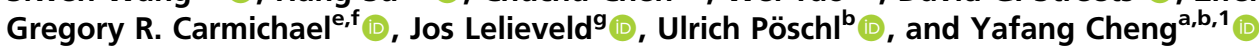

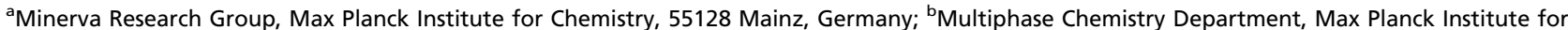 \\ Chemistry, 55128 Mainz, Germany; ' $E n e r g y$ Systems Division, Argonne National Laboratory, Lemont, IL 60439; d Laboratoire des Sciences du Climat et de

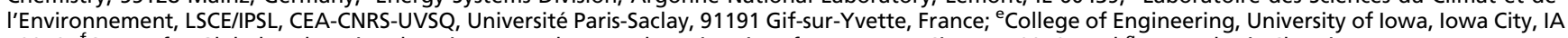 \\ 52242; ${ }^{f}$ Center for Global and Regional Environmental Research, University of lowa, lowa City, IA 52242; and ${ }^{9}$ Atmospheric Chemistry Department, Max \\ Planck Institute for Chemistry, 55128 Mainz, Germany
}

Edited by Guy P. Brasseur, Max Planck Institute for Meteorology, and accepted by Editorial Board Member Akkihebbal R. Ravishankara October 28, 2020 (received for review April 19, 2020)

The Chinese "coal-to-gas" and "coal-to-electricity" strategies aim at reducing dispersed coal consumption and related air pollution by promoting the use of clean and low-carbon fuels in northern China. Here, we show that on top of meteorological influences, the effective emission mitigation measures achieved an average decrease of fine particulate matter $\left(\mathrm{PM}_{2.5}\right)$ concentrations of $\sim 14 \%$ in Beijing and surrounding areas (the " $2+26$ " pilot cities) in winter 2017 compared to the same period of 2016, where the dispersed coal control measures contributed $\sim 60 \%$ of the total $\mathrm{PM}_{2.5}$ reductions. However, the localized air quality improvement was accompanied by a contemporaneous $\sim 15 \%$ upsurge of $\mathrm{PM}_{2.5}$ concentrations over large areas in southern China. We find that the pollution transfer that resulted from a shift in emissions was of a high likelihood caused by a natural gas shortage in the south due to the coal-to-gas transition in the north. The overall shortage of natural gas greatly jeopardized the air quality benefits of the coal-to-gas strategy in winter 2017 and reflects structural challenges and potential threats in China's clean-energy transition.

coal-to-gas action $\left|\mathrm{PM}_{2.5}\right|$ natural gas shortage | air pollution redistribution | environmental justice

$\mathbf{T}_{\mathrm{p}}^{\mathrm{h}}$ he "airpocalypse" in China stems from a multitude of air pollutants (1-3) that are associated with significant climate and health effects (4-8). Eliminating the severe fine particulate matter $\left(\mathrm{PM}_{2.5}\right.$; particulate matter with a diameter smaller than $2.5 \mu \mathrm{m}$ ) pollution smog has been perceived as a national priority, with the establishment of a coal-consumption cap that required the share of coal in the national primary energy mix to drop to below $65 \%$ in 2017 by a transition to cleaner natural gas and nonfossil energy sources (9). Coal reduction is, however, the crux of China's air pollution control (10). Fig. 1 shows the coalcontrol roadmap of China from 2010 through 2030. As of 2017 , over half of the world's coal consumption has occurred in China, accounting for $\sim 60 \%$ of the country's primary energy consumption (11). After effective coal reductions from the power sector and key energy-intensive industries (phase I), the further coal control in China has been focusing on the reduction of dispersed coal use in residential and small industrial facilities (phase II). The dispersed coal (the so-called "Sanmei" in Chinese) refers to raw coal, usually a high-polluting fuel with high ash residue, burned in noncentralized combustion facilities without end-of-pipe air pollutant treatment. The residential dispersed coal combustion in vast rural areas has been estimated to be a major contributor to high $\mathrm{PM}_{2.5}$ exposure and premature mortality in China $(7,12-14)$.

Since early 2017 , a series of clean-heating actions have been implemented in Beijing and its neighboring provinces, especially in the " $2+26$ " cities located along the air pollution transport channel of the Beijing-Tianjin-Hebei (BTH) region (Beijing, Tianjin, and 26 other cities in Hebei, Shanxi, Shandong, and Henan provinces) $(15,16)$. The major dispersed coal control measures include replacing traditional household coal-fired stoves with wall-mounted natural gas heaters ("coal-to-gas") or electric stoves ("coal-to-electricity") and eliminating the small industrial coal-fired steam boilers and construction materials industrial kilns (brick, ceramic, and lime industries) (17). The changes in coal consumption related to individual measures are given in Fig. 1.

Combining the ground-based measurements, localized emission estimates, and chemical transport model simulations, we show that, although air pollution in the northern $2+26$ pilot cities has been greatly improved by the emission mitigation measures, the coal-to-gas action in winter 2017 has caused a severe natural gas shortage in the rest of China (18, 19 and SI Appendix, section S1), which necessitated the use of more polluting alternative energy sources and led to a deteriorated air quality in the gasshortage regions.

\section{Significance}

Improving air quality is an important driving force for China's move toward clean energy and the extensive implementation of the "coal-to-gas" policy. Our analysis shows, however, that a shortage of natural gas during the implementation of the action in northern China has led to the transfer of pollution emissions and deterioration of air quality for large areas and populations in southern China during winter 2017. Our finding highlights the importance and necessity of synergy between environmental and energy policymaking to address the grand challenge of an actionable future to achieve the cobenefits of air quality, human health, and climate.

Author contributions: H.S. and Y.C. designed research and conceived the study; S.W. performed research and analyzed data; C.C. supported the data visualization; W.T. supported the meteorology validation; B.Z. provided the MEIC inventory and regional emission factors; D.G.S., Z.L., G.R.C., J.L., and U.P. commented on the results and manuscript; and S.W., H.S., and Y.C. wrote the paper.

The authors declare no competing interest.

This article is a PNAS Direct Submission. G.P.B. is a guest editor invited by the Editorial Board.

This open access article is distributed under Creative Commons Attribution-NonCommercialNoDerivatives License 4.0 (CC BY-NC-ND).

${ }^{1}$ To whom correspondence may be addressed. Email: h.su@mpic.de or yafang.cheng@ mpic.de.

This article contains supporting information online at https://www.pnas.org/lookup/suppl/ doi:10.1073/pnas.2007513117/-/DCSupplemental. 


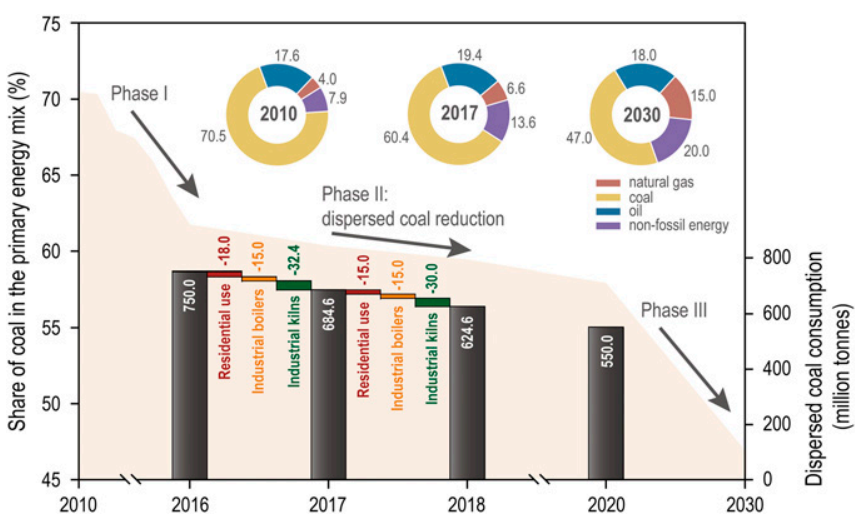

Fig. 1. The roadmap of coal control in China from 2010 to 2030 . The light orange shaded area shows the share of coal in the primary energy mix for 2010-2030 (11) with three-phased coal controls (phase I: in the power section and key energy-intensive industries; phase II: toward dispersed coal reductions; and phase III: pertaining to clean-energy development). The black bars indicate the dispersed coal consumption for 2016-2018 and 2020 with source decomposition for sectoral changes (17). The doughnut charts show the primary energy structures of China in 2010, 2017, and 2030, respectively $(11,37)$. Note: Energy data for Hong Kong, Macau, and Taiwan are not included here.

\section{Results}

Improved Air Quality in the Coal-To-Gas Cities. To assess the overall air quality benefits from the coal-to-gas action and other measures regarding dispersed coal reductions in winter 2017, we conducted a synthesis analysis of ground-based measurements of $\mathrm{PM}_{2.5}$ and gas pollutants, including sulfur dioxide $\left(\mathrm{SO}_{2}\right)$, nitrogen dioxide $\left(\mathrm{NO}_{2}\right)$, and carbon monoxide (CO) (SI Appendix, Fig. S1); emission change estimates; and chemical transport model simulations over eastern China. Ground-based measurements recorded at over 1,600 atmospheric monitoring sites showed that the $\mathrm{PM}_{2.5}$ concentrations declined dramatically in the heating period 2017 compared to the same period of 2016 over almost the entire northern China (SI Appendix, Figs. S2A and $\mathrm{S} 3 A$ ). Here, data from the last 2 mo (November and December) of each year are used to represent the heating period in winter. We discarded other heating months in the analyses because the coal-to-gas action has been temporarily halted in early 2018 due to the natural gas shortage (20). The average $\mathrm{PM}_{2.5}$ concentrations dropped by $41.8 \%\left(53.6 \mu \mathrm{g} \cdot \mathrm{m}^{-3}\right)$ over the $2+26$ cities (see SI Appendix, Fig. S4A for other air pollutants) and $60.7 \%\left(68.9 \mu \mathrm{g} \cdot \mathrm{m}^{-3}\right)$ over Beijing in the heating period 2017. Interestingly, across the North-South Central Heating Supply Line denoted in Fig. 2-a historical boundary from the 1950s that geographically distinguishes the northern territories with central heating supply in winter from southern China-the contemporaneous $\mathrm{PM}_{2.5}$ concentrations, however, mostly increased.

To account for the meteorological influence on the interannual variability of air pollution (21-24), GEOS-Chem model simulations were performed for 2016-2018, with anthropogenic emission inputs fixed to the 2016 monthly levels. The model framework and determination of meteorological effects are described in Materials and Methods, with model evaluations on meteorological parameters (SI Appendix, Fig. S5) and surface $\mathrm{PM}_{2.5}$ (SI Appendix, Fig. S6 and section S4), as well as sensitivity examinations on the emission intensity and model spatial resolution (SI Appendix, Fig. S7). Our modeling results suggest that the meteorological effects contributed an average $\sim 28 \%$ decrease of $\mathrm{PM}_{2.5}\left(\sim 36 \mu \mathrm{g} \cdot \mathrm{m}^{-3}\right)$ in the heating period 2017 relative to the 2016 level over the $2+26$ cities in northern China (SI Appendix, Fig. S3B) and $40 \%$ over Beijing, which is comparable to the $\sim 42 \%$ estimation inferred from a recent study on Beijing's
$\mathrm{PM}_{2.5}$ based on Weather Research and Forecasting meteorological inputs (25). The meteorological effects were then deduced month by month from the total observed relative changes in $\mathrm{PM}_{2.5}$ concentrations, which resulted in a residue of $13.8 \%\left(17.7 \mu \mathrm{g} \cdot \mathrm{m}^{-3}\right)$ net $\mathrm{PM}_{2.5}$ decrease over the $2+26$ cities (Fig. $2 A$ ). The net decreases in $\mathrm{SO}_{2}, \mathrm{NO}_{2}$, and $\mathrm{CO}$ concentrations were $36.7 \%\left(21.6 \mu \mathrm{g} \cdot \mathrm{m}^{-3}\right)$, $8.1 \%\left(5.5 \mu \mathrm{g} \cdot \mathrm{m}^{-3}\right)$, and $16.0 \%\left(0.37 \mathrm{mg} \cdot \mathrm{m}^{-3}\right)$, respectively.

We estimated the emission reductions from the dispersed coal control measures over the $2+26$ cities by assembling the sectorspecific dispersed coal-reduction activities, the converted natural gas and electricity coal consumption, and the regional average sector- and fuel-specific emission factors (SI Appendix, Table S1). It turned out that these dispersed coal control measures led to $43.7 \mathrm{Gg}(15.3 \%), 64.6 \mathrm{Gg}(13.8 \%), 7.8$ to $9.3 \mathrm{Gg}$ (1.0 to $1.2 \%)$, and $892.1 \mathrm{Gg}(16.2 \%)$ reductions in primary $\mathrm{PM}_{2.5}, \mathrm{SO}_{2}$, $\mathrm{NO}_{x}$, and $\mathrm{CO}$ emissions in the heating period 2017 (see Materials and Methods and SI Appendix, Fig. S8 for detailed data and step-by-step budgets), respectively, based on total emissions in the heating period 2016 from the Multi-resolution Emission Inventory for China (MEIC) inventory (ref. 26; shown in SI Appendix, Table S2).

The total emission reductions of air pollutants from all effective emission mitigation measures (e.g., the desulfurization, denitrification, dust removal, and facility upgrades in the industry and power sectors; residential clean heating and cooking; and upgrades of vehicle fuels and fleets; refs. 26 and 27) were estimated according to the sectoral reductions in primary $\mathrm{PM}_{2.5}$, $\mathrm{SO}_{2}$, and $\mathrm{NO}_{x}$ emissions over the $\mathrm{BTH}$ region during 2016-2017 derived from the MEIC inventory (27). Due to the lack of information for $\mathrm{CO}$ over the $\mathrm{BTH}$ region, we took the national average sectoral reductions during 2016-2017 (26). We considered all residential emission reductions in 2017 resulting from the dispersed coal emission reductions. Compared to other emission mitigation measures, these dispersed coal control measures dominated the total emission reductions for primary $\mathrm{PM}_{2.5}$ and $\mathrm{CO}(\sim 90 \%)$ in the heating period 2017 and accounted for about $40 \%$ and $10 \%$ for $\mathrm{SO}_{2}$ and $\mathrm{NO}_{x}$, respectively, with the remaining portions mainly from the more stringent industrial emission standards and industry upgrades (27). Thus, the total reductions in primary $\mathrm{PM}_{2.5}, \mathrm{SO}_{2}, \mathrm{NO}_{x}$, and $\mathrm{CO}$ emissions were estimated at $17 \%, 34 \%, 11 \%$, and $18 \%$, respectively.

We further assigned these relative emission changes to the baseline MEIC emissions for 2016 over the $2+26$ cities and performed model simulations for the heating period 2017 (SI Appendix, section S5). The modeling results suggest that these emission reductions led to an average 9.2\% decrease in the $\mathrm{PM}_{2.5}$ concentrations compared to the simulated $\mathrm{PM}_{2.5}$ concentrations in the heating period 2016 over these regions. Hence, the simulated reduction in $\mathrm{PM}_{2.5}$ concentrations achieved by all effective emission mitigation measures is comparable to the net observed $\mathrm{PM}_{2.5}$ decrease over the $2+26$ cities during the heating period 2016-2017. More modeling scenarios by zeroing out emission reductions from different dispersed coal control measures show that these specific measures accounted for $62 \%$ of the total emission-reduction-induced $\mathrm{PM}_{2.5}$ decreases over the $2+26$ cities in the heating period 2017. Among the dispersed coal control measures, the coal-to-gas action alone accounted for about $60 \%$ of the dispersed coal emission-reduction-induced $\mathrm{PM}_{2.5}$ decreases over these regions. These results demonstrate the crucial importance and high efficiency of the clean-energy transition to air-pollution control.

Deterioration of Air Quality in the Gas-Shortage Regions. After accounting for the meteorological influence, the remaining changes in $\mathrm{PM}_{2.5}$ concentrations, however, showed significant increases in large areas outside the northern $2+26$ cities in eastern China in the heating period 2017 compared to the same period of 2016 (Fig. $2 A$ and see SI Appendix, section S6 for Northeast China). 


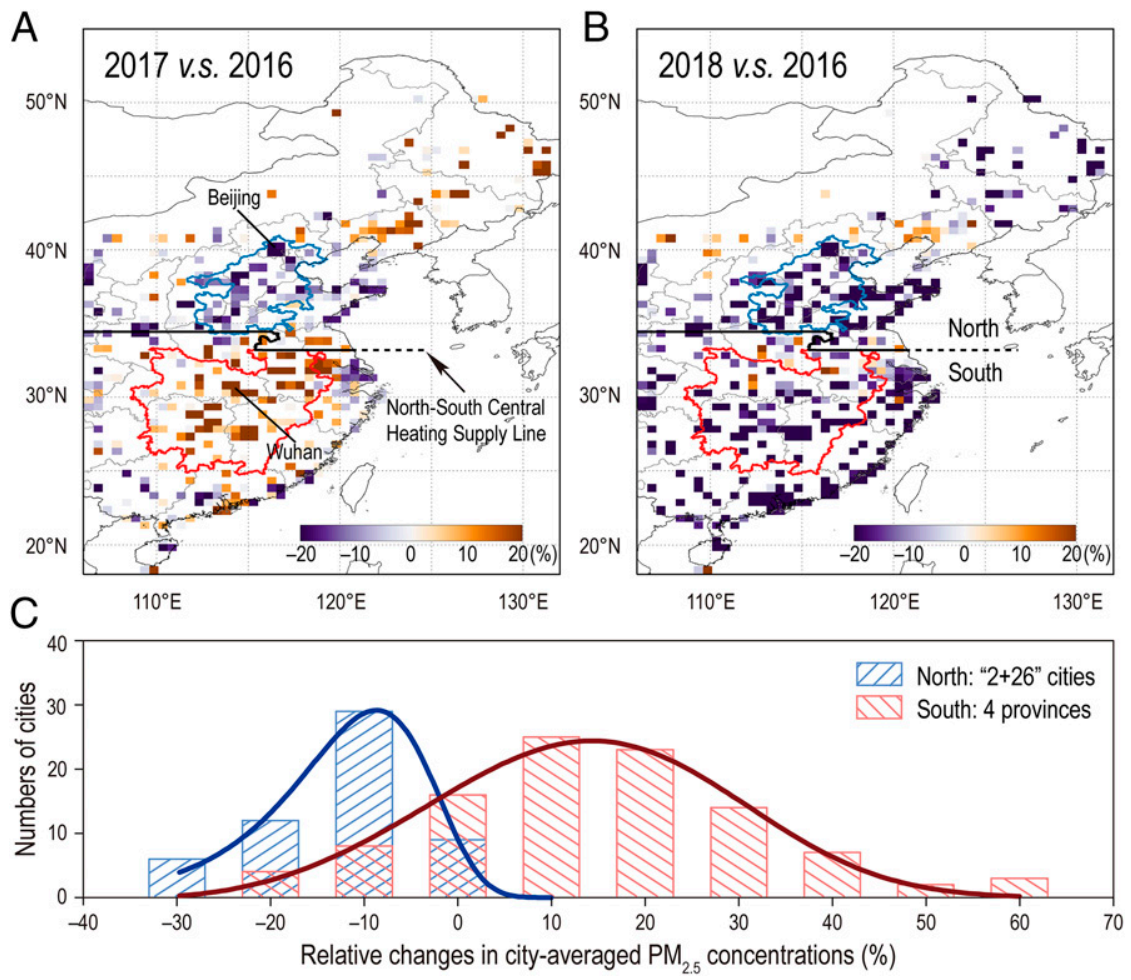

Fig. 2. Significant north-south regional discrepancies in ambient $\mathrm{PM}_{2.5}$ changes during the heating period 2017. ( $A$ and $B$ ) The emission-induced relative changes of ground-based $\mathrm{PM}_{2.5}$ concentrations in the heating period (November-December) $2017(A)$ and $2018(B)$ contemporaneously compared to the 2016 level with meteorological effect adjustment. $(C)$ The distribution of adjusted $\mathrm{PM}_{2.5}$ changes for the studied northern (28 cities; marked with a blue solid line in $A$ and $B$ ) and southern (51 cities; marked with a red solid line in $A$ and $B$ ) regions. Black solid lines in $A$ and $B$ represent the North-South Central Heating Supply Line. Vertical bars in $C$ show the numbers of cities with decreased (negative) or increased (positive) $\mathrm{PM}_{2.5}$ concentrations in November and December 2017 for both regions; colored curves represent fitting curves with a Weibull function.

The upsurge of ambient $\mathrm{PM}_{2.5}$ was especially notable over four inland provinces (including Hubei, Hunan, Anhui, and Jiangxi; in total, 51 cities) adjacent to the North-South Central Heating Supply Line in southern China, with an average net increase of $14.5 \%\left(9.5 \mu \mathrm{g} \cdot \mathrm{m}^{-3}\right)$. Fig. $2 C$ shows a distinct distribution of the meteorologically adjusted relative changes in $\mathrm{PM}_{2.5}$ concentrations in these southern 51 cities (red) against that in the northern $2+26$ cities (blue). Note that the meteorological effects actually contributed a $5.6 \%\left(3.7 \mu \mathrm{g} \cdot \mathrm{m}^{-3}\right)$ decrease in $\mathrm{PM}_{2.5}$ concentrations over the four southern provinces (SI Appendix, Fig. S3B).

To explore the possible factors that could have an impact on the changes in air pollutant emissions or concentrations in these four southern provinces in the heating period 2017, we first quantified the impact of natural source emissions by zeroing out the relevant emissions in the model (i.e., the biomass burning, biogenic, dust, sea salt, soil, lightning, and volcano emissions). Results suggest that these natural source emissions caused only a $1.8 \%$ increase in surface $\mathrm{PM}_{2.5}$ concentrations over these southern regions in the heating period 2017 relative to the 2016 level. We also noticed an $\sim 1 \mathrm{~K}$ decrease in air temperature over these regions in the heating period 2017 compared to the same period of 2016. Its impact on the additional use of fuels for heating is, however, expected to be small, inferring from the stable residential fuel consumption during winter (monthly temperature differences up to $8 \mathrm{~K}$ ) in similar southern cities (28). Moreover, based on model simulations with our estimated emission reductions in the northern $2+26$ cities and the MEIC emissions for 2016 and 2017 for other areas in China, we found that the declined air pollution in the northern regions and the regional or local nonlinear atmospheric processes led to a $1.2 \%$ decrease of $\mathrm{PM}_{2.5}$ in the four southern provinces in the heating period 2017 relative to the 2016 level (SI Appendix, section S5 and Fig. S9A). The above evaluations imply that some unaccounted additional anthropogenic emissions of air pollutants are the only possible major driving force for the deteriorated air pollution over these southern regions in the heating period 2017.

To ensure the implementation of the coal-to-gas action, the Chinese authorities have increased domestic natural gas production, supplemented by acquisitions from major international exporters. However, we found that the national natural gas consumption increased by only 2.1 billion cubic meters in volume (bcm) in the heating period 2017 compared to the same period of 2016 (see materials in ref. 18), far below the estimated increments required in the coal-to-gas action in northern China (i.e., 3.8 to $5.1 \mathrm{bcm}$ for the two heating months; Materials and Methods). A recent policy notice released by the Chinese National Energy Administration (19) has also confirmed the nationwide natural gas shortage during the coal-to-gas action in winter 2017 (SI Appendix, sections S1 and S3). Since the natural gas supply was made a priority for use in coal-to-gas homes in northern China (16), cross-regional transfers from the natural gas quotas for other regions in China were inevitable in that winter.

Although the natural gas shortage was nationwide in winter 2017, we noticed that the above-mentioned four southern provinces were confronted with the greatest difficulties in the natural gas shortfall, according to reports from local agencies (e.g., $\sim 20 \%$ natural gas deficits in Hubei and Hunan provinces; 22 to $33 \%$ in Hefei, the capital of Anhui province; and 22\% in Jiangxi province; more information is shown in ref. 18). For example, the cutoff of natural gas supply usually develops in a "light-to-severe" sequence from the use in industrial processes and industrial fuels to natural gas vehicles, public-services sectors, urban heating, and residential users (29). However, in winter 2017, the purchase of residential natural gas was even limited to $150 \mathrm{~m}^{3}$ per month 
for each home in Wuhan, the capital of Hubei province-only one-third of the normal gas demands for an urban family (ref. 30 and Materials and Methods). According to the annual energy consumption statistical data, the industrial coal consumption (excluding the nonenergy coal use) in these four southern provinces increased by $5.0 \%$ in 2017 compared to 2016, in contrast to the $6.0 \%$ decreases for the nation's total; the residential part decreased slightly by $1.4 \%$, also lower than the $3.9 \%$ national decreases (31). Such a natural gas shortage in the south due to the coal-to-gas action in the north may have led to the use of more polluting alternative energy sources and, consequently, a shift in emissions that caused the significant $\mathrm{PM}_{2.5}$ upsurge over these four southern provinces in the heating period 2017 (Fig. 2A).

Analyses on the evolution of the meteorologically adjusted $\mathrm{PM}_{2.5}, \mathrm{SO}_{2}, \mathrm{NO}_{2}$, and $\mathrm{CO}$ concentrations in both nonheating (July-October) and heating periods during 2016-2018 can provide further hints on the emission changes in these northern and southern regions in the heating period 2017. As shown in Fig. 3 (see more in SI Appendix, Fig. S4B), in the nonheating period, these air pollutants showed synchronous declining tendencies over both regions, reflecting the regular progress of emission mitigation throughout China in recent years (for primary $\mathrm{PM}_{2.5}$ and $\mathrm{CO}$ mainly in residential and industry sectors and $\mathrm{SO}_{2}$ and $\mathrm{NO}_{x}$ mainly in industry and power sectors) $(26,27)$. In the heating period, these air pollutants remained in consistent decline during 2016-2018 in the north; however, they exhibited a distinct upward pattern in the south in 2017, with $\mathrm{PM}_{2.5}, \mathrm{NO}_{2}$, and $\mathrm{CO}$ concentrations increased by $14.5 \%, 3.2 \%$, and $6.0 \%$ compared to 2016 , respectively, and $\mathrm{SO}_{2}$ decreased by $6.4 \%$. The south-shift pattern in the heating period 2017 can be better distinguished in the discrepancies of $\mathrm{PM}_{2.5}\left(\Delta \mathrm{PM}_{2.5}\right), \mathrm{SO}_{2}$ $\left(\Delta \mathrm{SO}_{2}\right), \mathrm{NO}_{2}\left(\Delta \mathrm{NO}_{2}\right)$, and $\mathrm{CO}(\Delta \mathrm{CO})$ concentrations between the nonheating and heating periods during 2016-2018. In contrast to the significant declining tendencies in $\Delta \mathrm{PM}_{2.5}, \Delta \mathrm{SO}_{2}$, $\Delta \mathrm{NO}_{2}$, and $\Delta \mathrm{CO}$ in the north, they surged up to $43.4 \mu \mathrm{g} \cdot \mathrm{m}^{-3}$ for $\Delta \mathrm{PM}_{2.5}, 5.8 \mu \mathrm{g} \cdot \mathrm{m}^{-3}$ for $\Delta \mathrm{SO}_{2}, 18.6 \mu \mathrm{g} \cdot \mathrm{m}^{-3}$ for $\Delta \mathrm{NO}_{2}$, and 0.35 $\mathrm{mg} \cdot \mathrm{m}^{-3}$ for $\Delta \mathrm{CO}$ in the heating period 2017 in the south. Such a regional air pollution transfer did not occur in the heating period 2018 (Fig. 3) when natural gas supply was sufficient, and no significant upsurge of $\mathrm{PM}_{2.5}$ was found in either the northern or the southern regions in that winter (Fig. 2B) (SI Appendix, section $\mathrm{S} 2$ ).

The distinctive regional decoupling of air pollution tendencies in the heating period 2017 demonstrates a dominant role of the cross-regional natural gas transfers on the redistribution of air pollution from the northern coal-to-gas regions to other areas of the country. However, for such a short-term unexpected emergency event, the existing emission inventories (e.g., the MEIC) are not able to provide correct trend analyses for most air pollutants over the affected regions without considering the shortterm energy transition and related additional emissions due to the lack of monthly and local energy consumption data (see $S I$ Appendix, Table S2, section S5, and Fig. S9 for more information). Therefore, we conducted a diagnostic evaluation of the changes in air pollutant emissions during the natural gas shortage for the most likely affected residential and industry sectors in the four southern provinces. A conservative estimate of $20 \%$ natural gas deficits for these regions in the heating period 2017 was made, according to natural gas activities reported from local agencies (see materials in ref. 18), which corresponds to at least a total of $0.8 \mathrm{bcm}$ natural gas in the two heating months (Materials and Methods). The alternative energy source to natural gas was expected to be added in the forms of, for feasible examples, coaland oil-fired boilers in industry and public-services sectors (the backup or outdated facilities reserved for emergency use), electric heaters and air conditioners in urban households, and coalor biofuel-fired stoves in rural areas. Assuming coal as the dominant alternative energy source (other types of fuels, e.g., oil and biofuels, would have more negative impacts on air quality; ref. 13), to compensate for the energy deficits from the $0.8-\mathrm{bcm}$ natural gas shortfall, 1.9 million tons $(\mathrm{Mt})$ of coal would have to be added in the four southern provinces in view of the equivalent heat value (considering a factor of 1.2 for higher thermal efficiency of gas-fired facilities; Materials and Methods).

Given scarce sectoral energy activities and facility information during the short-term natural gas shortage in winter 2017, we took the regional average sector- and fuel-specific emission factors provided by the MEIC inventory for 2016 (SI Appendix, Table S1) as the lower limit, because they represent the alreadyimproved emission control levels under strict environmental management in recent years (26). Using these emission factors,
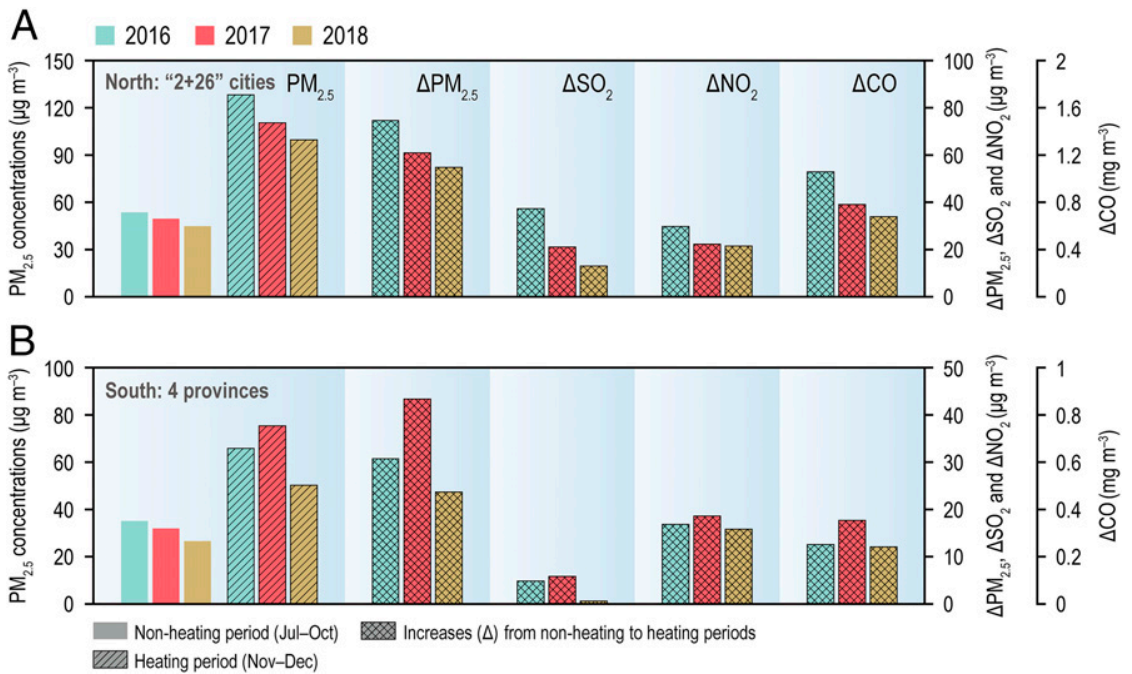

Fig. 3. South-shifted air pollution pattern in the heating period 2017 . The leftmost graph shows the mean $P M_{2.5}$ concentrations over the $2+26$ cities in the north $(A)$ and the four provinces in the south $(B)$ of China in the nonheating and heating periods during 2016-2018. The right four graphs show the increases in $\mathrm{PM}_{2.5}\left(\Delta \mathrm{PM}_{2.5}\right), \mathrm{SO}_{2}\left(\Delta \mathrm{SO}_{2}\right), \mathrm{NO}_{2}\left(\Delta \mathrm{NO}_{2}\right)$, and $\mathrm{CO}(\Delta \mathrm{CO})$ from the nonheating to heating periods. The interannual changes of meteorological effects on air pollutants were adjusted based on 2016. 
we estimated the net emission increases induced by the additional coal use at $2.7 \%(6.7 \mathrm{Gg})$ for primary $\mathrm{PM}_{2.5}, 5.4 \%(18.2$ $\mathrm{Gg})$ for $\mathrm{SO}_{2}, 0.5 \%(2.5 \mathrm{Gg})$ for $\mathrm{NO}_{x}$, and $3.4 \%(143.5 \mathrm{Gg})$ for $\mathrm{CO}$ in the four southern provinces in the heating period 2017 , discarding the uneven distribution of the additional coal use between residential and industry sectors (Materials and Methods). Considering the fact that contingency residential stoves and industrial boilers are mostly in low-maintenance and nonoptimal operational status or phased out by recent environmental regulation, their actual emission factors for air pollutants can be much higher than the present values (32), as shown in SI Appendix, Table S1. Thus, using these more realistic emission factors as the upper limit, we estimated the net emission increases induced by the additional coal use at $32.5 \%(80.4 \mathrm{Gg})$ for primary $\mathrm{PM}_{2.5}, 18.9 \%(63.8 \mathrm{Gg})$ for $\mathrm{SO}_{2}, 1.7 \%(8.8 \mathrm{Gg})$ for $\mathrm{NO}_{x}$, and $6.9 \%(286.8 \mathrm{Gg})$ for $\mathrm{CO}$.

With these estimates, we conducted model simulations by assigning the additional air pollutant emissions to the MEIC emissions for 2017 over the four southern provinces. Note that the MEIC inventory for 2017 has considered the annual technological improvements of emission factors for air pollutants attributable to the stringent emission mitigation measures in the four southern provinces (i.e., emission reductions of $5.7 \%$, $22.1 \%, 2.4 \%$, and $2.7 \%$ for primary $\mathrm{PM}_{2.5}, \mathrm{SO}_{2}, \mathrm{NO}_{x}$, and $\mathrm{CO}$ in the heating period 2017, respectively, compared to the same period of 2016), but it has not accounted for the possible shortterm emission upsurges due to the use of more polluting energy alternatives during the natural gas shortage (SI Appendix, Table S2 and section S5). Our modeling results suggest that these additional emissions would result in additional concentration increases of 1.7 to $21.5 \%$ for $\mathrm{PM}_{2.5}, 4.2$ to $16.8 \%$ for $\mathrm{SO}_{2}, 0.2$ to $2.2 \%$ for $\mathrm{NO}_{2}$, and 1.9 to $5.5 \%$ for $\mathrm{CO}$ in these southern regions in the heating period 2017, compared to the simulated concentrations in the same period of 2016 . Hence, the net simulated changes in the $\mathrm{PM}_{2.5}$ concentrations after accounting for the additional emissions can largely explain the net observed $\mathrm{PM}_{2.5}$ upsurge $(14.5 \%)$ over these southern regions during the heating period 2016-2017. Because that the additional $\mathrm{SO}_{2}$ emissions have not surpassed the distinct emission reductions $(22.1 \%)$ achieved from the mitigation measures, the net observed $\mathrm{SO}_{2}$ concentration still decreased.

It should also be noted that the magnitudes of these additional emissions are expected to be significantly lower than their actual levels in the four southern provinces, because most of the factors applied on the estimates of the additional coal use are on the conservative side in this study-e.g., that 1) the $0.8 \mathrm{-bcm}$ natural gas dispatch derived from the $20 \%$ natural gas deficits is only 27 to $47 \%$ of the total estimated amounts $(1.7$ to $3.0 \mathrm{bcm})$ received by the northern coal-to-gas regions; 2) the neglect of oil and biofuels as alternative energy sources and the adopted discrepancy in thermal efficiency between gas- and coal-fired facilities (a factor of 1.2; Materials and Methods) also contribute to an underestimation; and 3) in the industrial processes for alumina and nonferrous metals production, emission factors for primary $\mathrm{PM}_{2.5}$ from coal combustion can even be 50 times higher than the present value from the MEIC inventory for 2016 (33). Considering these amplifiers, the actual additional emissions of air pollutants during the energy transition ("gas-to-others") can reasonably surpass the reductions of $\mathrm{PM}_{2.5}, \mathrm{NO}_{x}$, and $\mathrm{CO}$ or greatly offset those of $\mathrm{SO}_{2}$ achieved by the emission mitigation measures and act as a major driving force for the surges of total emissions and concentrations of air pollutants (or the smaller decreases of $\mathrm{SO}_{2}$ ) in these four southern provinces in the heating period 2017. Thus, there is a high likelihood that the actual additional emissions of air pollutants induced by the more polluting energy alternatives to natural gas played a major role in deteriorating the air quality over these four provinces in southern China in the heating period 2017.

\section{Discussion and Policy Implications}

Fig. 4 decomposes the changes in $\mathrm{PM}_{2.5}$ pollution and coal and natural gas consumption for each driving force in the northern $2+26$ cities and the four southern provinces during the heating period 2016-2017. The regional redistribution of air pollution, triggered mainly by the coal-to-gas action in northern China in the context of the severe natural gas shortage, may greatly

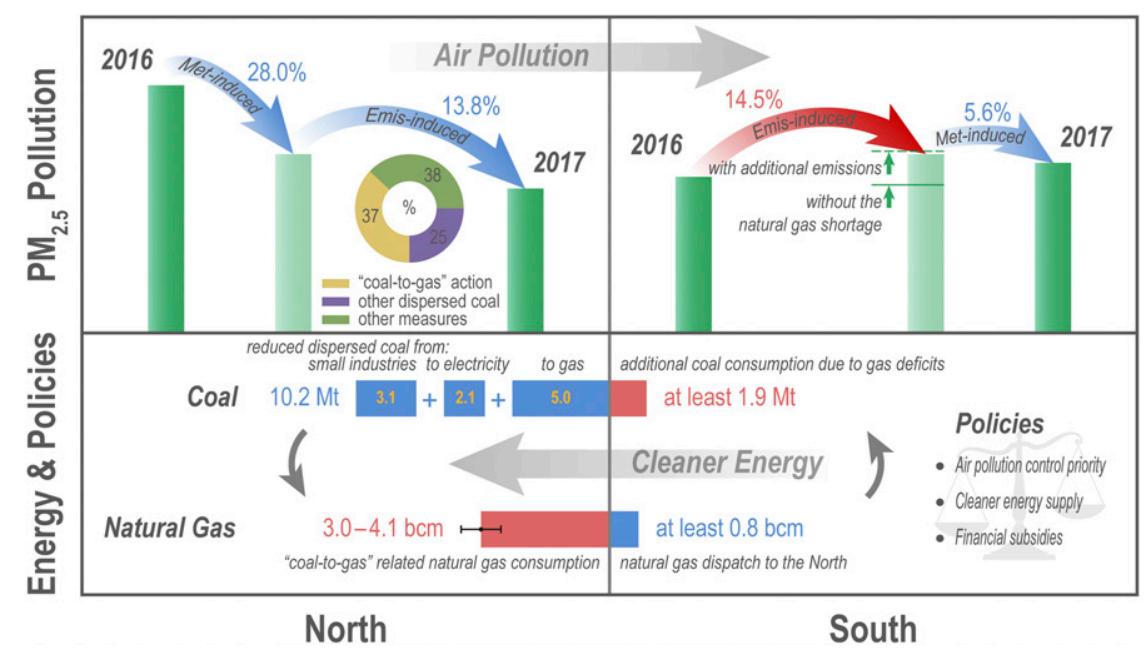

Fig. 4. Policy determinants of the regional redistribution of air pollution in China. In Upper, vertical bars show the observed $P M_{2.5}$ concentrations (green) over the $2+26$ cities in the north and the four provinces in the south in the heating period 2016-2017, and the meteorological adjusted PM 2.5 concentrations (light green) that decouple the contributions from MI (Met-induced) and El (Emis-induced) changes during the two periods. The doughnut chart in Upper Left shows the model-estimated relative contributions to the EI PM 2.5 decreases from the coal-to-gas action, other dispersed coal control measures, and the rest of the emission mitigation measures in the northern $2+26$ cities. The solid and dashed lines in Upper Right denote the PM 2.5 levels without and with the natural gas shortage-related additional emissions, respectively, in the four southern provinces. In Lower, horizontal bars show the energy-transition-related changes in coal and natural gas consumption during the heating period 2016-2017 for the two studied regions. The blue and red colors denote negative (decreases in 2017) and positive (increases in 2017) changes, respectively. The error bar shows the range of natural gas consumption required by the coal-to-gas action in the north during the heating period 2017. Units of coal, million tons; natural gas, billion cubic meters in volume. 
jeopardize the overall air quality benefits to be expected from the transition toward cleaner energy and environmental justice. However, given sufficient natural gas supply as in winter 2018, such regional air pollution transfer can be avoided, and a nationwide decline in $\mathrm{PM}_{2.5}$ pollution can be achieved, as shown in Fig. $2 B$. It also remains to be seen whether the coal-to-gas action can be retained as a long-term policy without governmental subsidies on facilities and energy use, especially in rural areas (34). Our findings highlight the necessity of a coordinated framework for the energy-environment nexus, where the potential cobenefits for climate and human health should be fully considered from local to regional scales (35).

China is implementing its energy transition under a tight schedule. In 2030, the shares of natural gas and nonfossil energy are estimated to increase to $15 \%$ and $20 \%$ of the primary energy mix, respectively (36) (Fig. 1). By that time, the importance of natural gas as part of the regional air quality controls will be further highlighted. However, there is increasing recognition that the demand-supply imbalances of natural gas will significantly widen over the Asia-Pacific region in the next decade $(37,38)$, and, thus, a repetition of the severe natural gas shortage of winter 2017 and the consequent redistribution of air pollution will still be a high risk in China (39). Concerning China's upsurge of natural gas demands and national energy security (see more in SI Appendix, section S7), coordinated efforts that strive for the introduction of new and improved clean technologies and the effective utilization of coal, gas, and alternative energy sources are needed to sustain the national and regional energy demands while achieving air quality goals. The risks and uncertainties in China's clean-energy transition are also worthy of consideration by policymakers in other coal-dominated countries. An efficient and well-coordinated energy transition in China will benefit not only regional air quality and human health, but also the sustainable development of the world.

\section{Materials and Methods}

Air Pollution Measurements. The hourly ground-based measurement data for ambient $\mathrm{PM}_{2.5}, \mathrm{SO}_{2}, \mathrm{NO}_{2}$, and $\mathrm{CO}$ concentrations have been recorded at more than 1,600 atmospheric monitoring sites managed by the Ministry of Ecology and Environment (MEE) of China since 2013. These urban stations geographically cover all prefecture-level districts of mainland China, following the requirements of the national technical regulation for ambient air quality monitoring (40). Each monitoring site reports the average concentrations of air pollutants over the surrounding 0.5 to $4.0 \mathrm{~km}$ (in radius) areas. The minimum number of monitoring sites for a single city depends on its urban population and size, and for this study, we applied data from 158 and 255 sites located within the studied $2+26$ cities in northern China and the four inland provinces (including Hubei, Hunan, Anhui, and Jiangxi) in southern China (Fig. 2), respectively. The 24-h average concentrations were used for the analyses during 2016-2018. Note that gas measurements after September 1, 2018 were reported for the reference state $(298.15 \mathrm{~K}, 1,013.25$ $\mathrm{hPa})$, while the earlier data were reported for the standard state $(273 \mathrm{~K}$, $1,013.25 \mathrm{hPa}$ ) (41). For interannual comparison, we have converted data after September 1, 2018 to the standard state. The $\mathrm{PM}_{2.5}$ concentrations were consistently measured and reported under the ambient conditions during the studied period.

Model Configuration and Evaluation. The GEOS-Chem model (version 11-01) simulations were conducted for 2016-2018 to determine the meteorological effects on the surface air pollution changes over eastern China. GEOS-Chem is a global chemical transport model for air composition studies that simulates multiple physical and chemical processes, driven by assimilated meteorological data from the Goddard Earth Observing System (GEOS) of NASA/ Global Modeling and Assimilation Office, with 72 hybrid sigma-pressure levels in the vertical (14 layers in the lowest $2 \mathrm{~km}$ ) extending up to 0.01 $\mathrm{hPa}$. The simulation was performed at a $2.5^{\circ}$ longitude $\times 2^{\circ}$ latitude horizontal resolution with 47 vertical layers (in reduced mode), compiled with the full chemical mechanism (standard) that includes the secondary organic aerosol (SOA) formation. The MERRA-2 reanalysis meteorological data (updated every 1 to $3 \mathrm{~h}$ ) were used in this study, which cover a continuous period from the year 1980 onwards and have been widely evaluated for multiple parameters by using satellite measurements (42-45). At least 1-y spin-up simulation was conducted to minimize the effects from initial concentration fields.

The global anthropogenic emissions of atmospheric species were provided by the Emission Database for Global Atmospheric Research (v4.2) inventory for $2012(46,47)$ and were replaced over China by the MEIC inventory (v1.3) for the studied years $(26,48-50)$. The MEIC database includes monthly airpollutant emissions for $\mathrm{SO}_{2}, \mathrm{NO}_{x}, \mathrm{CO}$, ammonia, volatile organic compounds (VOCs), primary $\mathrm{PM}_{2.5}$ and coarse $\mathrm{PM}$, as well as primary $\mathrm{PM}_{2.5}$ components of black carbon (BC) and organic carbon (OC), at a $0.25^{\circ}$ resolution (http:// www.meicmodel.org/). Besides primary organic matter (calculated as 1.6 times the primary $\mathrm{OC}$ emissions), $\mathrm{BC}$, and primary sulfate ( $3 \%$ of the $\mathrm{SO}_{2}$ emissions), the residual $\mathrm{PM}_{2.5}$ was considered as anthropogenic dust emissions and assigned to the dust emission inputs in the model, following Philip et al. (51). The international ship emissions for $\mathrm{CO}$ and $\mathrm{NO}_{x}$ were provided by the International Comprehensive Ocean-Atmosphere Data Set inventory (52) and for $\mathrm{SO}_{2}$ from the Arctic Research of the Composition of the Troposphere from Aircraft and Satellites inventory, based on the work by Eyring et al. (53, 54). The aircraft emissions of $\mathrm{NO}_{x}$ were from the Aviation Emissions Inventory Code (v2.1) inventory (55-57). The Global Fire Emissions Database (v4) was used for biomass-burning emissions (58). Biogenic VOCs and $\mathrm{NO}_{x}$ emissions were calculated by the Model of Emissions of Gases and Aerosols from Nature (v2.1) (59). Other natural source emissions included the soil and lightning emissions for $\mathrm{NO}_{x}(60,61)$, volcanic $\mathrm{SO}_{2}$ emissions from AeroCom point source data (62), mineral dust emissions based on the dust entrainment and deposition scheme $(63,64)$, and sea salt emissions $(65)$. The daily 24-h average concentrations of air pollutants were derived for the surface layer of the model, which typically has a height of about $120 \mathrm{~m}$ in winter over eastern China. The mass concentration of $\mathrm{PM}_{2.5}$ was calculated for components including sulfate, nitrate, ammonium, BC, organic aerosols, SOA, dust, and sea salt at $35 \%$ relative humidity to follow common measurement protocols (51). Model-performance evaluations on the meteorological parameters and the interannual variations in surface $\mathrm{PM}_{2.5}$ concentrations are provided in detail in SI Appendix, section S4.

To examine the role of model spatial resolution on the estimates of meteorological effects, we also conducted the one-way nested GEOS-Chem simulations over China and Southeast Asia $\left(60^{\circ} \mathrm{E}\right.$ to $150^{\circ} \mathrm{E}, 11^{\circ} \mathrm{S}$ to $\left.55^{\circ} \mathrm{N}\right)$ for 2016-2018 (for details, see refs. 66 and 67). The nested GEOS-Chem model was performed at a $0.625^{\circ} \times 0.5^{\circ}$ horizontal resolution with 47 vertical layers, driven by the MERRA-2 meteorological data. Similar emission inputs were used following the setting for the global GEOS-Chem simulations. To quantify the contributions of natural source emissions to surface $\mathrm{PM}_{2.5}$ concentrations over eastern China, parallel model simulations without the relevant emissions were conducted for 2016-2018.

To evaluate the effects of nonlinear chemistry in the atmosphere in the heating period 2017 over the northern $2+26$ cities and the four southern provinces, we conducted two simulation scenarios for the heating period 2017: 1) with the total relative reductions in primary $\mathrm{PM}_{2.5}, \mathrm{SO}_{2}, \mathrm{NO}_{x}$, and $\mathrm{CO}$ emissions derived in this study (i.e., by $17 \%, 34 \%, 11 \%$, and $18 \%$, respectively) assigned to the MEIC emissions for 2016 over the northern 2+26 cities and the MEIC emissions for 2017 over other areas in eastern China; and 2) with the MEIC emissions for 2016 over the entire area of eastern China.

Meteorological Effects and Adjustments. The observed relative changes in air pollutant concentrations between two time periods were linearly decomposed into two pieces of sources: meteorology-induced (MI) and emissioninduced (EI) relative changes. The former was determined by the meteorological factors and chemical mechanism in the GEOS-Chem model with a fixed setting of emission inputs. Here, the year 2016 was selected as a basis for calculation. The MI relative change in the observed concentration $\left(\Omega_{\text {obs }}\right)$ of year $i$ was considered to be a first approximation of the modeled $\left(\Omega_{\text {mod }}\right)$ relative change:

$$
\mathrm{MI}_{\mathrm{i}}=\left(\Omega_{\mathrm{adj}, \mathrm{i}}-\Omega_{\mathrm{obs}, \mathrm{i}}\right) / \Omega_{\mathrm{obs}, 2016}=\left(1-\Omega_{\mathrm{mod}, \mathrm{i}} / \Omega_{\mathrm{mod}, 2016}\right),
$$

where $\Omega_{\mathrm{adj}, i}$ presents the adjusted observed concentrations of year $i$ with the compensatory of $\mathrm{Ml}$ piece of concentration changes $\left(\Omega_{\mathrm{obs}, 2016} \times \mathrm{MI}_{i}\right)$ on the observed concentrations of year $i$. This approach has the advantage of yielding local meteorological effects that account for the nonlinear impacts over a variety of pollution levels and terrains. It then derives the adjusted observed concentrations of year $i$ : 


$$
\Omega_{\mathrm{adj}, \mathrm{i}}=\Omega_{\mathrm{obs}, \mathrm{i}}+\Omega_{\mathrm{obs}, 2016} \times\left(1-\Omega_{\mathrm{mod}, \mathrm{i}} / \Omega_{\mathrm{mod}, 2016}\right) .
$$

The difference between the $\mathrm{Ml}$ and the total relative changes in the observed concentration of air pollutants in year $i$ is attributed to the El part:

$$
\mathrm{El}_{\mathrm{i}}=\Omega_{\mathrm{mod}, \mathrm{i}} / \Omega_{\mathrm{mod}, 2016}-\Omega_{\mathrm{obs}, \mathrm{i}} / \Omega_{\mathrm{obs}, 2016} .
$$

Similar evaluation of meteorological effects has been widely applied $(22,23$, $25,27,68,69)$. The potential bias of this approach is mainly associated with the model performance on reproducing the real meteorological fields and the air pollutant concentrations, although the model used here is considered a state-of-the-art tool and data source for the external adjustments on (or comparators to) ground-based measurements (70-73). Sensitivity examination showed that using different anthropogenic emission inputs (e.g., the MEIC for 2010 , with $45.7 \%$ and $107.5 \%$ higher primary $\mathrm{PM}_{2.5}$ and $\mathrm{SO}_{2}$ emissions than 2016) merely produced a small influence (relative error $<10 \%$ ) on the meteorological-effect estimates for both studied regions. The different scales of the model and ground-based measurements can also introduce systematic bias. However, similar meteorological-effect estimates were generated-erasing $31.6 \%$ and $8.1 \% \mathrm{PM}_{2.5}$ concentrations over the northern $2+26$ cities and the four southern provinces, respectively-by using the regional-scale nested GEOS-Chem simulations (SI Appendix, Fig. S7). These indicated that the above-mentioned systematic and random bias can be well reduced via regional averaging and comparison between relative changes. The tendencies of $\mathrm{PM}_{2.5}$ changes were robust over the studied two regions in this study.

Emission-Change Estimates for Major Air Pollutants. The emission changes of primary $\mathrm{PM}_{2.5}$ and gas pollutants $\mathrm{SO}_{2} \mathrm{NO}_{x}$ and $\mathrm{CO}$ were estimated for the $2+26$ cities in northern China and the four inland provinces in southern China. Although the MEIC inventory provides monthly air pollutant emissions until 2017, the downscaled activity data on the national level for 2017 and the annual provincial energy consumption data can introduce large bias to the 2-mo emission-change analyses over the specific regions in this study (26). Instead, we used the sector-specific dispersed coal reduction data provided by the China Dispersed Coal Governance Report (17) and the converted natural gas consumption for the northern $2+26$ cities. Lacking monthly energy data at a provincial level (similar bottleneck for the MEIC inventory), the changes in energy activities for the four southern provinces were based on reports from local agencies on the natural gas shortage (18) and the equivalent energy alternatives. The sector- and fuel-specific emission factors for the two regions were adopted from the MEIC inventory for 2016; for contingency residential stoves and industrial boilers used in the southern regions in the heating period 2017 during the natural gas shortage, we also applied a set of more realistic emission factors in the emission estimates (SI Appendix, Table S1). Total MEIC emissions for the heating period 2016 were used as the basis for the regional relative emission-change analyses (SI Appendix, Table S2).

According to the China Dispersed Coal Governance Report (17), the cleanheating measures have prevented a total of $65.4 \mathrm{Mt}$ of dispersed coal use over the BTH and surrounding areas in 2017, including $18 \mathrm{Mt}$ from the residential clean heating in about 6 million homes (of 4.75 million homes in the $2+26$ cities, about $70 \%$ transited to natural gas and $30 \%$ to electricity) and 15 and $32.4 \mathrm{Mt}$ due to the phaseout of small industrial boilers and construction materials industrial kilns.

There are typically four heating months during winter in the northern coal-to-gas cities. The residential coal consumption for heating is about 3 tons per year (i.e., 0.75 tons per heating month) in each home. For an urban family, a single commercial wall-mounted natural gas heater usually consumes 12 to $15 \mathrm{~m}^{3}$ of natural gas per heating day (74), with the upper bound for cold indoor temperature or cold walls. For rural families, natural gas use was reported at over $20 \mathrm{~m}^{3}$ per heating day (75). We adopted the 15- to $20-\mathrm{m}^{3}$ daily natural gas use per coal-to-gas home in this study, which yielded

1. H. Akimoto, Global air quality and pollution. Science 302, 1716-1719 (2003).

2. D. D. Parrish, T. Zhu, Climate change. Clean air for megacities. Science 326, 674-675 (2009).

3. K. Aunan, M. H. Hansen, S. Wang, Introduction: Air pollution in China. China Q. 234, 279-298 (2018)

4. M. O. Andreae, C. D. Jones, P. M. Cox, Strong present-day aerosol cooling implies a hot future. Nature 435, 1187-1190 (2005).

5. V. Ramanathan, Y. Feng, Air pollution, greenhouse gases and climate change: Global and regional perspectives. Atmos. Environ. 43, 37-50 (2009).

6. R. T. Burnett et al., An integrated risk function for estimating the global burden of disease attributable to ambient fine particulate matter exposure. Environ. Health Perspect. 122, 397-403 (2014).
3.8 to $5.1 \mathrm{bcm}$ natural gas consumption in two heating months for the 4.2 million coal-to-gas homes in northern China.

In the northern $2+26$ cities, the involved households are 4.75 million homes, corresponding to $7.1 \mathrm{Mt}$ of dispersed coal reductions (5.0 Mt by coal-to-gas and 2.1 Mt by coal-to-electricity) and 3.0- to $4.0-\mathrm{bcm}$ natural gas increments during the heating period 2017. The phaseout of small industrial boilers and kilns accounted for $44.0 \%$ and $36.5 \%$ of the total numbers in the BTH and surrounding areas, respectively (17), contributing 3.1 Mt of dispersed coal reductions in the 2-mo period. Thus, the reduced air pollution emissions were $41.5 \mathrm{Gg}$ for primary $\mathrm{PM}_{2.5}, 50.1 \mathrm{Gg}$ for $\mathrm{SO}_{2}, 6.5 \mathrm{Gg}$ for $\mathrm{NO}_{x}$ (the mass calculated as $\mathrm{NO}_{2}$ ), and $856.1 \mathrm{Gg}$ for $\mathrm{CO}$ from the residential dispersed coal reductions; and $2.9 \mathrm{Gg}$ for primary $\mathrm{PM}_{2.5}, 15.9 \mathrm{Gg}$ for $\mathrm{SO}_{2}, 10.1$ $\mathrm{Gg}$ for $\mathrm{NO}_{x}$, and $45.0 \mathrm{Gg}$ for $\mathrm{CO}$ from the phaseout of small industrial facilities. The additional 3.0- to $4.0-\mathrm{bcm}$ natural gas consumption produced 4.4 to $5.9 \mathrm{Gg} \mathrm{NO}_{x}, 4.0$ to $5.3 \mathrm{Gg} \mathrm{CO}$, and negligible primary $\mathrm{PM}_{2.5}$ and $\mathrm{SO}_{2}$. Considering the equivalent $2.1 \mathrm{Mt}$ of residential coals avoided by the coal-to-electricity as combusted in local coal-fired power plants, the corresponding emissions were $0.7 \mathrm{Gg}$ for primary $\mathrm{PM}_{2.5}, 1.4 \mathrm{Gg}$ for $\mathrm{SO}_{2}, 2.9 \mathrm{Gg}$ for $\mathrm{NO}_{x}$, and $4.4 \mathrm{Gg}$ for $\mathrm{CO}$. In summary, the net emission reductions due to these measures were estimated at $43.7 \mathrm{Gg}(15.3 \%)$ for primary $\mathrm{PM}_{2.5}, 64.6$ $\mathrm{Gg}(13.8 \%)$ for $\mathrm{SO}_{2}$, and $892.1 \mathrm{Gg}(16.2 \%)$ for $\mathrm{CO}$ in the $2+26$ cities in the heating period 2017 compared to the same period of 2016, while the reductions in $\mathrm{NO}_{x}$ were relatively small $(7.8$ to $9.3 \mathrm{Gg}$ and 1.0 to $1.2 \%$ ) due to the thermal $\mathrm{NO}_{x}$ formation and the higher combustion temperature of natural gas than coal. The avoided dispersed coal consumption through coal-to-electricity may also be compensated for through the electricity transmission from other provinces $(76,77)$, and excluding the corresponding emission increments will not cause significant bias in this study.

In the four southern provinces, we made a conservative estimate of $20 \%$ natural gas deficits in the heating period 2017, according to reports from local agencies (18). The total annual natural gas consumption (including the liquefied natural gas) for these provinces was $14.3 \mathrm{bcm}$ in 2017 (31). The fraction of natural gas consumption for the last 2 mo in annual totals was calculated as the national average $(23.7 \%)$ for 2016 (18). Hence, at least a total of $0.8-\mathrm{bcm}$ natural gas deficit was estimated in the heating period 2017 , corresponding to $1.9 \mathrm{Mt}$ of coal in view of the equivalent heat value [ $1 \mathrm{~m}^{3}$ of natural gas is equal to $1.862 \mathrm{~kg}$ of raw coal (31), with a factor of 1.2 for higher thermal efficiency of gas-fired facilities (78)]. The net air pollution emissions from the gas-to-coal transition were estimated based on two sets of emission factors shown in SI Appendix, Table S1: 1) the present regional average sector- and fuel-specific emission factors provided by the MEIC inventory for 2016, which generated the lower limit of the estimates; and 2) the emission factors for contingency residential and industrial facilities, which generated the upper limit. For the lower limit, we estimated the additional air pollutant emissions at $11.1 \mathrm{Gg}(4.5 \%)$ for primary $\mathrm{PM}_{2.5}, 23.7$ $\mathrm{Gg}(7.0 \%)$ for $\mathrm{SO}_{2}, 0.5 \mathrm{Gg}(0.1 \%)$ for $\mathrm{NO}_{x}$ and $260.3 \mathrm{Gg}(6.2 \%)$ for $\mathrm{CO}$, if burned in residential stoves; or $2.3 \mathrm{Gg}(0.9 \%)$ for primary $\mathrm{PM}_{2.5}, 12.7 \mathrm{Gg}$ $(3.8 \%)$ for $\mathrm{SO}_{2}, 4.5 \mathrm{Gg}(0.9 \%)$ for $\mathrm{NO}_{x}$, and $26.7 \mathrm{Gg}(0.6 \%)$ for $\mathrm{CO}$, if burned in industrial boilers. For the upper limit, these additional air pollutant emissions turned out to be $88.5 \mathrm{Gg}(35.8 \%)$ for primary $\mathrm{PM}_{2.5}, 38.8 \mathrm{Gg}$ $(11.5 \%)$ for $\mathrm{SO}_{2}, 6.2 \mathrm{Gg}(1.2 \%)$ for $\mathrm{NO}_{x}$, and $546.1 \mathrm{Gg}(13.0 \%)$ for $\mathrm{CO}$, if burned in residential stoves; or $72.2 \mathrm{Gg}(29.2 \%)$ for primary $\mathrm{PM}_{2.5}, 88.7 \mathrm{Gg}$ $(26.2 \%)$ for $\mathrm{SO}_{2}, 11.3 \mathrm{Gg}(2.2 \%)$ for $\mathrm{NO}_{x}$, and $27.4 \mathrm{Gg}(0.7 \%)$ for $\mathrm{CO}$, if burned in industrial boilers.

Data Availability. The ground-based air quality data from the MEE monitoring stations used to support the major findings of this study are accessible from https://beijingair.sinaapp.com/.

ACKNOWLEDGMENTS. This work is supported by the Max Planck Society (MPG). Y.C. was supported by the Minerva Program of MPG.

7. J. Lelieveld, J. S. Evans, M. Fnais, D. Giannadaki, A. Pozzer, The contribution of outdoor air pollution sources to premature mortality on a global scale. Nature $\mathbf{5 2 5}$, 367-371 (2015)

8. J. Lelieveld et al., Effects of fossil fuel and total anthropogenic emission removal on public health and climate. Proc. Natl. Acad. Sci. U.S.A. 116, 7192-7197 (2019).

9. State Council of the People's Republic of China, The air pollution prevention and control national action plan (2013). http://www.gov.cn/zwgk/2013-09/12/content_ 2486773.htm. Accessed 18 August 2020

10. Q. Zhang, K. He, H. Huo, Policy: Cleaning China's air. Nature 484, 161-162 (2012).

11. British Petroleum, Statistical review of world energy (2019). https://www.bp.com/en/ global/corporate/energy-economics/statistical-review-of-world-energy.html. Accessed 18 August 2020. 
12. J. Liu et al., Air pollutant emissions from Chinese households: A major and underappreciated ambient pollution source. Proc. Natl. Acad. Sci. U.S.A. 113, 7756-7761 (2016).

13. S. Tao et al., Quantifying the rural residential energy transition in China from 1992 to 2012 through a representative national survey. Nat. Energy 3, 567-573 (2018).

14. B. Zhao et al., Change in household fuels dominates the decrease in $\mathrm{PM}_{2.5}$ exposure and premature mortality in China in 2005-2015. Proc. Natl. Acad. Sci. U.S.A. 115 12401-12406 (2018).

15. National Development and Reform Commission of China, Wintertime clean heating plan in North China (2017-2021) (2017). https://www.ndrc.gov.cn/zcfb/zcfbtz/201712 t20171220_871052.html. Accessed 18 August 2020.

16. Ministry of Environmental Protection of China, Action plan on comprehensive control and treatment for autumn and winter air pollution of 2017-2018 over Jing-Jin-Ji and surrounding regions (2017). http://www.mee.gov.cn/gkml/hbb/bwj/201708/ t20170824_420330.htm. Accessed 18 August 2020.

17. Natural Resources Defense Council, China dispersed coal governance report 2018 (2018). http://nrdc.cn/information/informationinfo?id=190\&cook=1. Accessed $18 \mathrm{Au}$ gust 2020.

18. S. Wang, Integrated data and news on natural gas consumption/shortage in China (2019). https://dx.doi.org/10.17617/3.35. Accessed 18 August 2020.

19. National Energy Administration, Notice on resolving the issues in promoting the clean heating through the "coal-to-gas" and "coal-to-electricity" (2019). http://www.nea. gov.cn/2019-07/03/c 138195454.htm. Accessed 18 August 2020.

20. Reuters Staff, China's Hebei halts coal to gas heating conversion project: Report (2018). https://www.reuters.com/article/us-china-pollution-gas/chinas-hebei-haltscoal-to-gas-heating-conversion-project-report-idUSKBN1FJOCD. Accessed 18 August 2020.

21. W. Cai, K. Li, H. Liao, H. Wang, L. Wu, Weather conditions conducive to Beijing severe haze more frequent under climate change. Nat. Clim. Chang. 7, 257-262 (2017).

22. Q. Zhong et al., Distinguishing emission-associated ambient air $\mathrm{PM}_{2.5}$ concentrations and meteorological factor-induced fluctuations. Environ. Sci. Technol. 52, 10416-10425 (2018)

23. D. Ding, J. Xing, S. Wang, K. Liu, J. Hao, Estimated contributions of emissions controls, meteorological factors, population growth, and changes in baseline mortality to re ductions in ambient $\mathrm{PM}_{2.5}$ and $\mathrm{PM}_{2.5}$-related mortality in China, 2013-2017. Environ Health Perspect. 127, 067009 (2019).

24. H. Wang et al., The impacts of the meteorology features on $\mathrm{PM}_{2.5}$ levels during a severe haze episode in central-east China. Atmos. Environ. 197, 177-189 (2019)

25. J. Cheng et al., Dominant role of emission reduction in $\mathrm{PM}_{2.5}$ air quality improvement in Beijing during 2013-2017: A model-based decomposition analysis. Atmos. Chem Phys. 19, 6125-6146 (2019)

26. B. Zheng et al., Trends in China's anthropogenic emissions since 2010 as the consequence of clean air actions. Atmos. Chem. Phys. 18, 14095-14111 (2018).

27. Q. Zhang et al., Drivers of improved $\mathrm{PM}_{2.5}$ air quality in China from 2013 to 2017. Proc. Natl. Acad. Sci. U.S.A. 116, 24463-24469 (2019).

28. D. Zhu et al., Temporal and spatial trends of residential energy consumption and air pollutant emissions in China. Appl. Energy 106, 17-24 (2013).

29. Sina News, Behind the suspended "coal-to-gas": A new high of gas price and an upcoming gas shortage (2017). http://news.sina.com.cn/c/nd/2017-12-09/doc-ifypnyqi2635802.shtml. Accessed 18 August 2020.

30. Sina News, Wuhan limits the purchase of natural gas to 150 cubic metres per month each family (2017). http://finance.sina.com.cn/china/2017-12-21/doc-ifypxrpp3133492. shtml. Accessed 18 August 2020.

31. National Bureau of Statistics, China Energy Statistical Yearbook 2018 (China Statistics Press, Beijing, China, 2019)

32. M. Li et al., Anthropogenic emission inventories in China: A review. Natl. Sci. Rev. 4 834-866 (2017)

33. Y. Lei, Q. Zhang, K. B. He, D. G. Streets, Primary anthropogenic aerosol emission trends for China, 1990-2005. Atmos. Chem. Phys. 11, 931-954 (2011).

34. H. Sun, The four trends in the development of "coal-to-gas". Sinopec Monthly 10, 23-26 (2018).

35. J. Lelieveld, P. J. Crutzen, Indirect chemical effects of methane on climate warming Nature 355, 339-342 (1992).

36. National Development and Reform Commission of China, Energy production and consumption transition strategy (2016-2030) (2016). https://www.ndrc.gov.cn/zcfb/ zcfbtz/201704/t20170425 845284.html. Accessed 18 August 2020.

37. . British Petroleum, "Energy outlook 2035" (Tech. Rep., British Petroleum, London, UK, 2014).

38. Q. Ji, Y. Fan, M. Troilo, R. D. Ripple, L. Feng, China's natural gas demand projections and supply capacity analysis in 2030. Energy J. (Camb. Mass.) 39, 53-70 (2018).

39. National Energy Administration, "China's natural gas development report 2019" (Tech. Rep., Petroleum Industry Press, Beijing, China, 2019).

40. Ministry of Environmental Protection of China, Technical Regulation for Selection of Ambient Air Quality Monitoring Stations (On Trial) (China Environmental Science Press, Beijing, China, 2013).

41. Ministry of Ecology and Environment of China, A bulletin on the revision of the ambient air quality standard (GB 3095-2012) (2018). http://www.mee.gov.cn/ xxgk2018/xxgk/xxgk01/201808/t20180815_629602.html. Accessed 18 August 2020.

42. R. H. Reichle et al., Assessment of MERRA-2 land surface hydrology estimates. J. Clim. 30, 2937-2960 (2017).

43. K. Wargan et al., Evaluation of the ozone fields in NASA's MERRA-2 reanalysis. J. Clim 30, 2961-2988 (2017).

44. Y.-K. Lim, R. M. Kovach, S. Pawson, G. Vernieres, The 2015/16 El Niño event in context of the MERRA-2 reanalysis: A comparison of the tropical Pacific with 1982/83 and 1997/98. J. Clim. 30, 4819-4842 (2017).
45. V. Buchard et al., The MERRA-2 aerosol reanalysis, 1980 onward. Part II: Evaluation and case studies. J. Clim. 30, 6851-6872 (2017).

46. J. G. J. Olivier, A. F. Bouwman, C. W. M. van der Maas, J. J. M. Berdowski, Emission database for global atmospheric research (EDGAR). Environ. Monit. Assess. 31, 93-106 (1994).

47. J. G. J. Olivier, A. F. Bouwman, C. W. M. van der Maas, J. J. M. Berdowski, Emission database for global atmospheric research (EDGAR): Version 2.0. Stud. Environ. Sci. 65 651-659 (1995)

48. B. Zheng et al., High-resolution mapping of vehicle emissions in China in 2008. Atmos. Chem. Phys. 14, 9787-9805 (2014).

49. F. Liu et al., High-resolution inventory of technologies, activities, and emissions of coal-fired power plants in China from 1990 to 2010. Atmos. Chem. Phys. 15, 13299-13317 (2015)

50. M. Li et al., Mapping Asian anthropogenic emissions of non-methane volatile organic compounds to multiple chemical mechanisms. Atmos. Chem. Phys. 14, 5617-5638 (2014)

51. S. Philip et al., Anthropogenic fugitive, combustion and industrial dust is a significant, underrepresented fine particulate matter source in global atmospheric models. En viron. Res. Lett. 12, 044018 (2017).

52. C. Wang, J. J. Corbett, J. Firestone, Improving spatial representation of global ship emissions inventories. Environ. Sci. Technol. 42, 193-199 (2008).

53. V. Eyring, H. W. Köhler, J. van Aardenne, A. Lauer, Emissions from internationa shipping: 1. The last 50 years. J. Geophys. Res. 110, D17305 (2005)

54. V. Eyring, H. W. Köhler, A. Lauer, B. Lemper, Emissions from international shipping: 2 Impact of future technologies on scenarios until 2050. J. Geophys. Res. 110, D17306 (2005).

55. M. E. J. Stettler, S. Eastham, S. R. H. Barrett, Air quality and public health impacts of UK airports. Part I: Emissions. Atmos. Environ. 45, 5415-5424 (2011)

56. M. E. J. Stettler, A. M. Boies, A. Petzold, S. R. H. Barrett, Global civil aviation black carbon emissions. Environ. Sci. Technol. 47, 10397-10404 (2013).

57. N. W. Simone, M. E. J. Stettler, S. R. H. Barrett, Rapid estimation of global civil aviation emissions with uncertainty quantification. Transport. Res. D-TR. E 25, 33-41 (2013).

58. G. R. van der Werf et al., Global fire emissions and the contribution of deforestation, savanna, forest, agricultural, and peat fires (1997-2009). Atmos. Chem. Phys. 10 11707-11735 (2010)

59. A. B. Guenther et al., The model of emissions of gases and aerosols from nature version 2.1 (MEGAN2.1): An extended and updated framework for modeling biogenic emissions. Geosci. Model Dev. 5, 1471-1492 (2012).

60. R. C. Hudman et al., Steps towards a mechanistic model of global soil nitric oxide emissions: Implementation and space based-constraints. Atmos. Chem. Phys. 12, 7779-7795 (2012)

61. B. Sauvage et al., Remote sensed and in situ constraints on processes affecting tropical tropospheric ozone. Atmos. Chem. Phys. 7, 815-838 (2007)

62. S. A. Carn, K. Yang, A. J. Prata, N. A. Krotkov, Extending the long-term record of volcanic $\mathrm{SO}_{2}$ emissions with the ozone mapping and profiler suite nadir mapper. Geophys. Res. Lett. 42, 925-932 (2015).

63. C. S. Zender, H. Bian, D. Newman, Mineral dust entrainment and deposition (DEAD) model: Description and 1990s dust climatology. J. Geophys. Res. 108, D14 (2003).

64. C. S. Zender, D. Newman, O. Torres, Spatial heterogeneity in aeolian erodibility: Uniform, topographic, geomorphic, and hydrologic hypotheses. J. Geophys. Res. 108 D17 (2003).

65. L. Jaeglé, P. K. Quinn, T. S. Bates, B. Alexander, J.-T. Lin, Global distribution of sea salt aerosols: New constraints from in situ and remote sensing observations. Atmos. Chem. Phys. 11, 3137-3157 (2011).

66. Y. X. Wang, M. B. McElroy, D. J. Jacob, R. M. Yantosca, A nested grid formulation for chemical transport over Asia: Applications to CO. J. Geophys. Res. 109, D22307 (2004).

67. S. W. Wang et al., Growth in $\mathrm{NO}_{x}$ emissions from power plants in China: Bottom-up estimates and satellite observations. Atmos. Chem. Phys. 12, $4429-4447$ (2012)

68. C. Hong et al., Impacts of climate change on future air quality and human health in China. Proc. Natl. Acad. Sci. U.S.A. 116, 17193-17200 (2019)

69. Y. Zou, Y. Wang, Y. Zhang, J.-H. Koo, Arctic sea ice, Eurasia snow, and extreme winte haze in China. Sci. Adv. 3, e1602751 (2017).

70. A. M. Fiore et al., Evaluating the contribution of changes in isoprene emissions to surface ozone trends over the eastern United States. J. Geophys. Res. 110, D12303 (2005).

71. Y. Wang et al., Variations of $\mathrm{O}_{3}$ and $\mathrm{CO}$ in summertime at a rural site near Beijing Atmos. Chem. Phys. 8, 6355-6363 (2008).

72. L. N. Lamsal et al., Indirect validation of tropospheric nitrogen dioxide retrieved from the OMI satellite instrument: Insight into the seasonal variation of nitrogen oxides at northern midlatitudes. J. Geophys. Res. 115, D05302 (2010)

73. Y. Wang, Q. Q. Zhang, K. He, Q. Zhang, L. Chai, Sulfate-nitrate-ammonium aerosols over China: Response to 2000-2015 emission changes of sulfur dioxide, nitrogen oxides, and ammonia. Atmos. Chem. Phys. 13, 2635-2652 (2013).

74. Zhihu, Daily gas consumption amounts of the wall-mounted natural gas heaters (2018). https://zhuanlan.zhihu.com/p/52510742. Accessed 18 August 2020

75. NetEase News, Cost of natural gas device installation and use in residential home (2017). http://dy.163.com/article/D6JQBAOJ0512K1AT.html. Accessed 18 August 2020.

76. X. Zhou et al., An overview of power transmission systems in China. Energy 35 4302-4312 (2010)

77. D. Fang et al, Clean air for some: Unintended spillover effects of regional air pollution policies. Sci. Adv. 5, eaav4707 (2019)

78. T. Sun, A Technical Manual for Boiler Worker (Phoenix Science Press, Nanjing China, 2010). 